\title{
Occupational dose reduction at nuclear installations through work management and ALARA*
}

\author{
C. VIKTORSSON**, C. SCHIEBER***
}

(Manuscrit reçu le 14 novembre 1994,

révisé le 20 février 1995, accepté le 14 avril 1995)

\begin{abstract}
Work management, which is defined as the organisation, control and follow-up of radiation works to ensure that doses are ALARA ("as low as reasonably achievable"), is the responsibility of management. Radiation protection must be an integral part of the management of a nuclear installation in that good protection enhances safety and reliability of the installation and thus the economy of the plant. The upper as well as the middle and lower management must know ALARA and deal with doses as they deal with money. In this paper the authors introduce work management and ALARA concepts and review some recent experience gained from the application of those concepts at nuclear installations.
\end{abstract}

RÉSUMÉ L'organisation du travail, que l'on peut définir comme l'organisation, le contrôle et le suivi des travaux sous rayonnements ionisants mis en œuvre pour s'assurer que les expositions sont "ALARA", relève de la responsabilité des managers. L'application de la démarche d'optimisation de la radioprotection (ou démarche ALARA), tout en assurant une réduction du niveau des expositions, permet également d'améliorer la qualité des interventions et par conséquent la sûreté, la fiabilité ainsi que la situation économique des installations. La radioprotection doit donc faire partie intégrante de la gestion des installations nucléaires. Il importe que les responsables de tous les niveaux hiérarchiques s'engagent dans la démarche ALARA et adoptent une organisation visant à créer un véritable "système de gestion des expositions" basé sur le mode de gestion financière des installations. Dans cet article, les auteurs introduisent les concepts d'organisation du travail et d'ALARA. Ils présentent quelques expériences récentes en ce qui concerne l'application de ces concepts dans les installations nucléaires.

\section{Introduction}

Occupational dose reduction is important not only for the health and safety of the workforce but also because the associated requirement for a good management system enhances safety and reliability of the installation and thus the economy of the plant. Indeed, during the eighties and beginning of the nineties

\footnotetext{
* Communication présentée lors de la journée "Radioprotection" organisée dans le cadre de la conférence ENC'94 "Occupational Radiation Protection in NPPs", Lyon, 4 octobre 1994.

** Swedish radiation protection institute, S-171 16 Stockholm, Sweden.

*** Centre d'étude sur l'évaluation de la protection dans le domaine nucléaire (CEPN), BP 48, F-92263

Fontenay-aux-Roses Cedex, France.
} 
progress has been made and occupational doses have decreased in most countries and in particular in the OECD area [4]. However, there is no time for complacency because as plants become older there is a general tendency of increased maintenance and repair requirements. Moreover, ICRP Publication 60 , which recommends more stringent dose limits, further draws the attention to the exposure of workers and consequently to ways of reducing such exposure. Finally, the decommissioning and dismantling are additional factors to consider when entering the XXIst century. Radiation protection must face all these challenges since high standards of protection are required by the public and workforce in order to keep nuclear an acceptable source of energy. Work management and ALARA are in this context extremely important concepts.

\section{ALARA in radiation protection}

In addition to dose limitation, one of the basic principles of radiation protection is that "doses must be kept as low as reasonably achievable, economic and social factors being taken into account", i.e. the famous ALARA, or optimisation of radiation protection, principle. In other words, we could say that ALARA is to choose the best course of action available under some given circumstances.

The ALARA principle came into the radiation protection philosophy with the discovery of the late effects of radiation. In the early days, it was thought that there existed a threshold for radiation effects and consequently good protection meant keeping the exposures below that threshold. Later on, however, the situation was complicated by the fact that so-called stochastic effects of radiation were discovered - effects that appeared below the threshold for acute effects. Still today it is not clear whether these effects are valid for very small doses, but for reasons of prudence as well as theoretical considerations, practical radiation protection assumes these effects going down to zero dose. The proper approach, therefore, should strive for the reduction of doses as low as possible, ideally to zero. The cost of protection varies, however; an initial expenditure may result in significant dose reduction, but further expenditure produces progressively smaller reductions. Therefore, the objective of reaching zero dose is, although desirable, not compatible with adequate allocation of resources in society and with the distribution of risk among groups of people or individuals (Fig. 1).

To define the optimum solution, there is a need for setting reference monetary values for the unit of collective dose, in order to be able to compare the cost of protective actions with the associated reduction of exposure. This value, which is often referred to as the alfa value, seems to vary greatly between countries and even from one utility to another, but is typically in the order of 0.1 to 1 million US dollars per mansievert [1]. In some cases, instead of being fixed, the reference monetary value of the mansievert is expressed as an increasing function of the level of individual exposures, in order to reduce the dispersion of individual distribution of risks. 


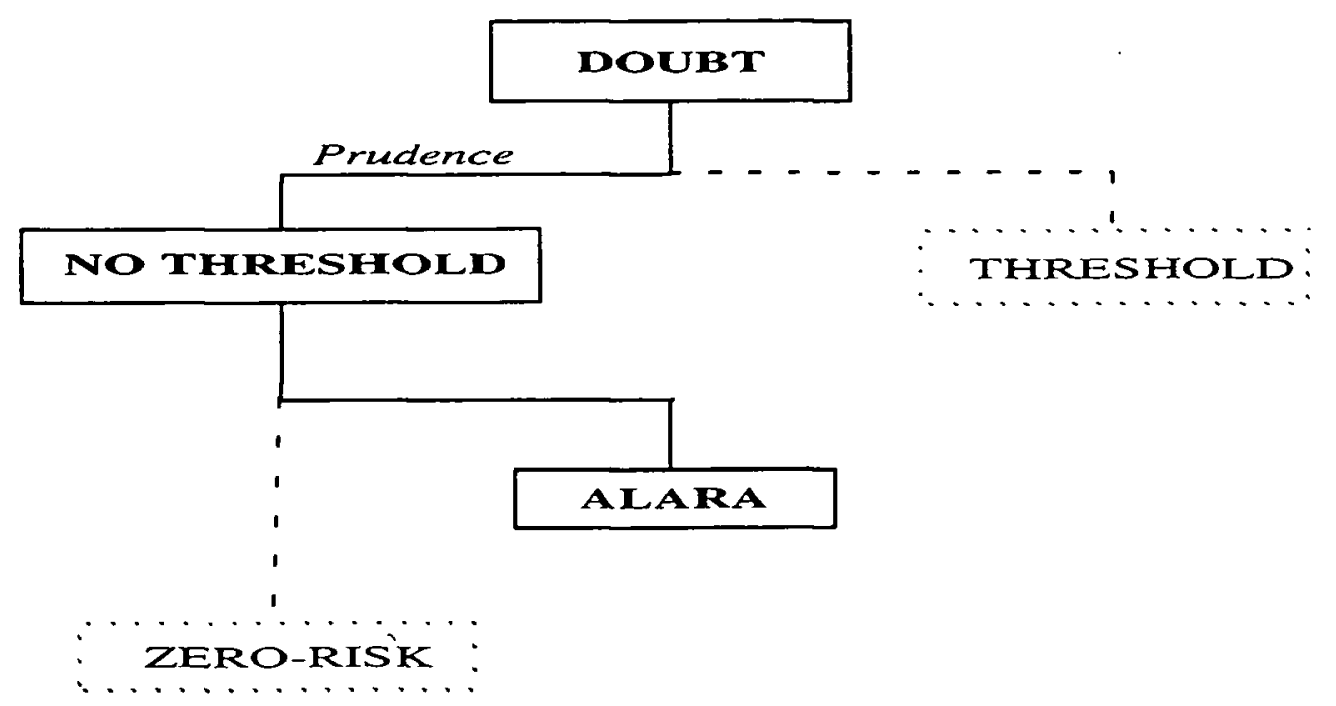

Fig. 1 - The foundation of the ALARA principle [3].

Les bases du principe ALARA, d'après [3].

Thus the ALARA principle has been introduced as a means to assist in defining the optimal solution of radiation protection problems.

\section{Work management to implement ALARA}

How to assure that doses are kept ALARA? The application of the ALARA principle means to adopt an approach which considers all the factors that contribute to the radiation doses, i.e. dose rates, duration of exposure and number of workers involved in the work. The collective dose $(S)$ resulting from any given operation can be expressed by the following equation : $S=d t N$, where $d$ is the ambient dose rate, $t$ is the duration of exposure and $N$ is the number of workers involved.

To get doses to the ALARA level, it is thus necessary to go through and review all the components that make up the doses, one by one, and judge their dose reduction potential in relation to their respective costs.

In certain cases, the reduction of these components may be measured directly. The dose rate $(d)$, for example, can be reduced by installing biological shields, the thicker the shield the lower the dose rate, or by removing radioactive sources from the place where to work, the more substances removed the lower the remaining dose rates. In such cases costs can fairly easily be attached to the measure in question. In other cases, it may be more difficult to couple the effect of any single measure and the resulting dose rates. The implementation of chemistry control, zinc injection, electropolishing, etc. has proven to result in efficient dose rate reduction techniques and they have led to remarkable results. However, no one of these alone seems to suffice, but implementing suitable combinations will generally result in significant dose reduction [11]. Due to their complexity and for economical reasons, finding justification for such measures may sometimes be difficult. 


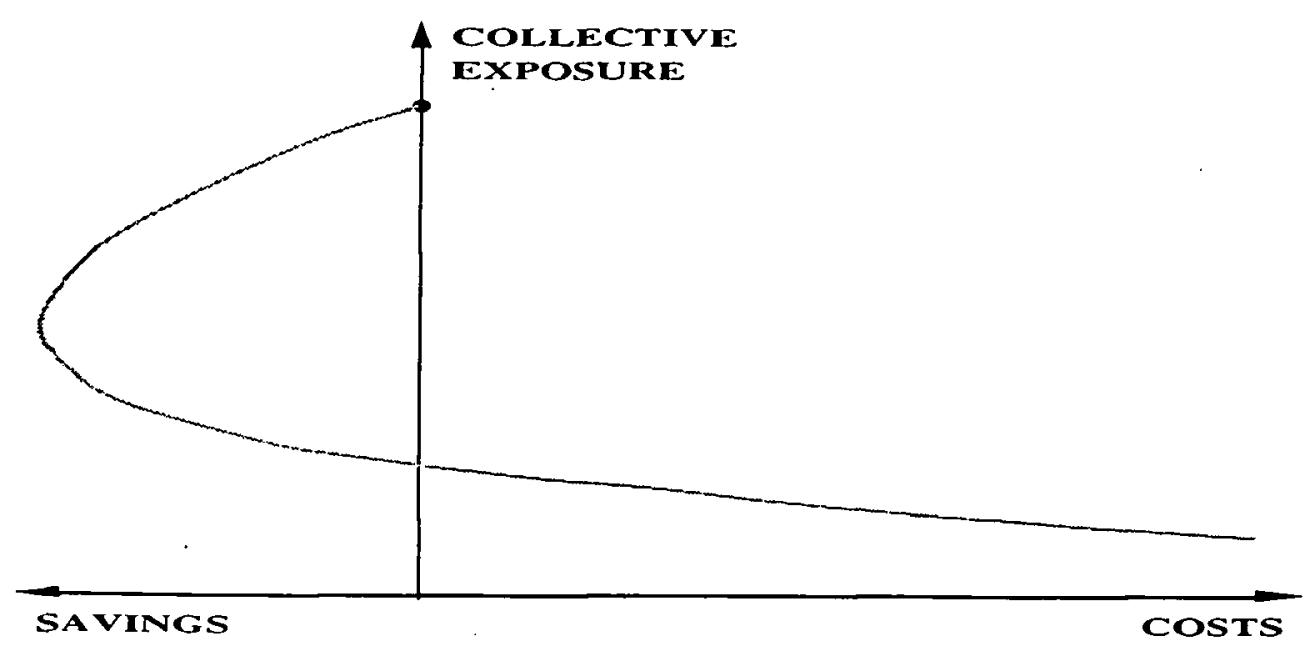

Fig. 2 - The benefits of radiological risk reduction [3].

Les bénéfices de la réduction du risque radiologique, d'après [3].

As far as the duration of exposure $(t)$ and the number of workers involved $(N)$ are concerned, examples of effective measures are the application of proper work organisation and training of the workforce. Also here, it is difficult to directly quantify the effect of introducing these factors on the exposure, but studies have shown that a great potential for reducing exposures can be obtained through work management actions without spending vast sums of money or even with savings of money (Fig. 2). Often as a result of good work management there also come economical gains through the more efficient use of the workforce and equipment.

The remaining part of this paper will primarily focus on techniques to manage the $t$ and $N$-factors, but it should once more be stressed that in any ALARA program all the relevant factors have to be considered in an integral way, i.e. also measures that can have an influence on the $d$-factor have to be considered.

\section{Quantification of the $\boldsymbol{t}$ and $\boldsymbol{N}$-factors}

Factors having direct or indirect impacts on the exposure time are :

i) working conditions (personal protections, working environment, etc.) ;

ii) worker characteristics (qualification, information about the work, experience, etc.) ;

iii) work organisation (scheduling, preparation, co-ordination, etc.).

The modification of one or several of the above factors will have a direct impact on the productivity of workers and then influence directly the exposure time and usually the costs of carrying out the work. 
How significant is this influence ? If one would be able to present quantitative evidence, in the form of gain in time, money, and dose by introducing such dose reduction measures, it would be much easier to make the case for the measures and get them accepted by management. Many case studies exist today, and some examples are given below. Several national and international groups have started to work on this matter in order to draw some conclusions from the experience that exists today and to develop some methods of quantification based on the case studies existing. In particular, one could mention the work that is underway at the CEPN in France [8] and within the OECD Nuclear energy agency (NEA) [5].

\section{The OECD group}

The OECD group is developing a "good practice" manual, where the various aspects of work management will be identified and to each of them will be attached some examples of good practices quantifying the gain in time, dose and cost of their introduction. In doing this, the OECD group has also discussed the question of "rework" and the importance of developing a management system for the characterisation and elimination of rework (rework results when an activity must be redone because it did not resolve or it worsened the original problem and the results did not meet expectations [6]. Such a management system could then help in dealing with any problem which could be eliminated by the use of work management. A framework for such a system contains the following [6] :

- reduce unnecessary dose due to rework,

- establish work management controls to reduce rework,

- quantify dose, time and resources being spent on rework,

- establish a system to track and monitor rework,

- identify the causes of rework,

- establish a definition for rework.

Rework seems to contribute significantly to the collective doses at nuclear power plants and they should consequently consider developing a structure to minimise such rework. It has been estimated that of the order of $10 \%$ of the collective dose during a normal refuelling outage is due to rework [6].

To illustrate rework, the following swedish example is given. Having installed new metallic insulation on piping in the containment, it was discovered at one plant that "adhesive labels" containing PVC had been left on the pipes. These had been used as reference points for some photo documentation of the pipings in the containment. The newly installed insulation had to be taken off the piping in order to remove these "labels" because they contained chlorine and could produce aggressive hydrochloric acid. This work, which took two days and gave rise to 0.225 manSv ( $7 \%$ of outage dose) could have been avoided "if the personnel had been fully aware of the type of material that can be used in the power plant" [7]. 


\section{French studies}

French studies tend to confirm that a great potential for reducing exposure can be obtained through work management actions. The objectives of the studies were to quantify the impact of various work management factors on the exposure time and to include these quantifications within a model aiming at calculating the variations of doses and operational costs associated with protective actions modifying one or several factors [9].

In order to quantify the impact of the factors listed above (working conditions, workers characteristics, work organisation), a review of the literature was performed. It allowed to estimate the impact of the modification of some working conditions on exposure times. The results were complemented by a survey carried out at five French nuclear power plants and by feedback analysis of routine maintenance and post-incidental operations. Table I presents a summary of the main results.

\section{TABLE I}

Impact on exposure time of factors related to working conditions Impact sur la durée de l'exposition des facteurs relatifs aux conditions de travail

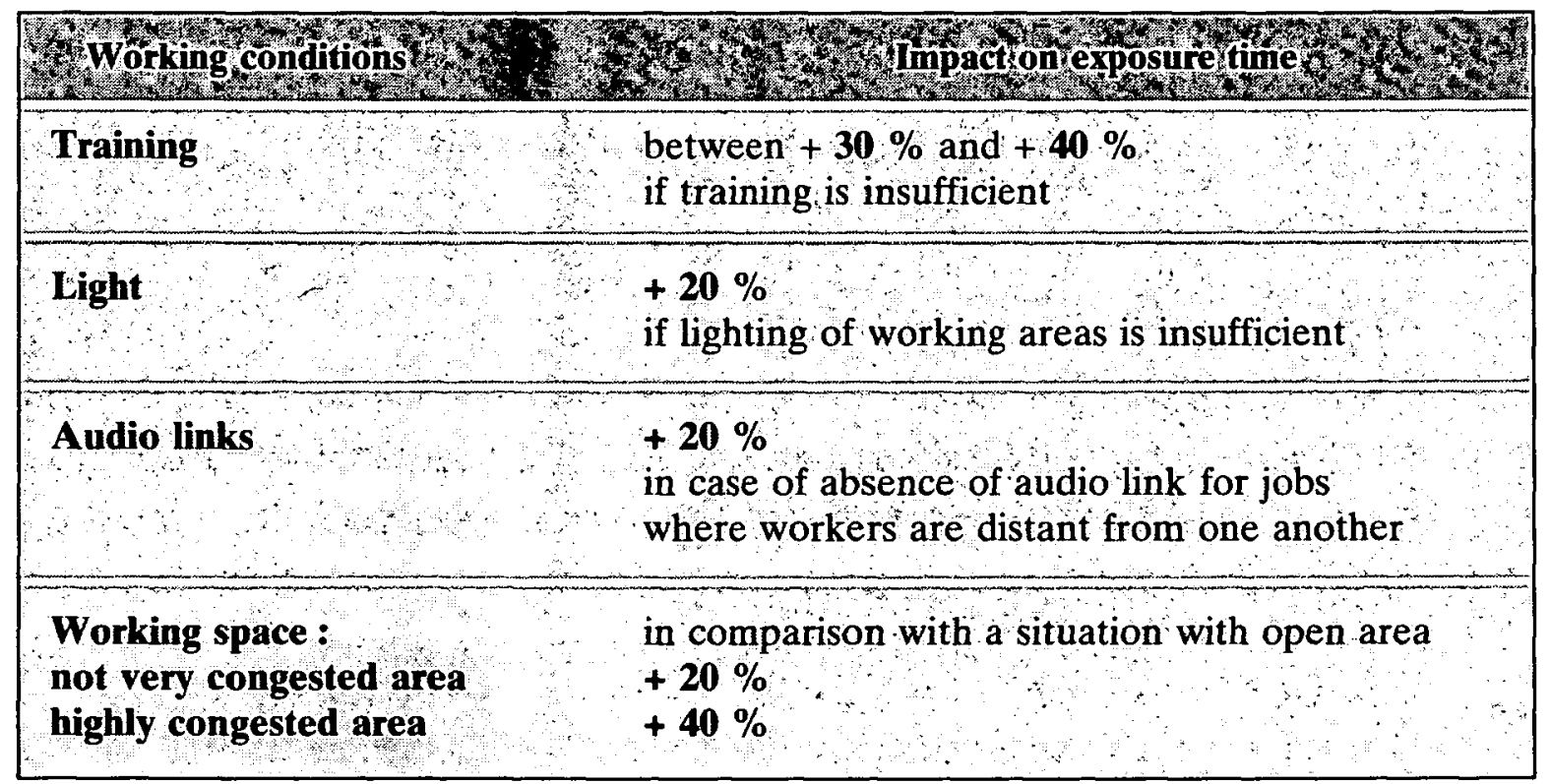

The direct impact of some factors such as the general organisation of tasks or the preparation of work is more difficult to quantify. Nevertheless, the importance of these factors has been underscored by the analysis of routine maintenance and post-incidental operations. Indeed, these operations could be due to mishaps. The main causes of mishaps are :

- bad preparation of work (for example : scaffoldings not adapted, problems of schedules....),

- tools not adapted or malfunctioning,

- lack of training of workers. 
It was also shown that these types of mishaps could be avoided by the implementation of specific ALARA programs. For example, Table II presents the average percentage of mishap dose for the same operations performed in several French units as a function of the degree of integration of ALARA at the different stages of the preparation, follow-up, and feedback experience analysis.

TABLE II

Average percentage of mishaps for 22 jobs on reactor vessel heads Pourcentage moyen d'incidents pour 22 interventions sur des couvercles de cuves de réacteurs

\begin{tabular}{|lc|}
\hline $\begin{array}{l}\text { Degree of integration of ALARA programs } \\
\text { No application of a structured ALARA procedure }\end{array}$ & $\begin{array}{c}\text { Average percentage of dose } \\
\text { due tom mishaps (min-max ) }\end{array}$ \\
\hline $\begin{array}{l}\text { No specific ALARA preparation, but application } \\
\text { of the ALARA procedure during the operation }\end{array}$ & $70 \%(50-80)$ \\
\hline \hline $\begin{array}{l}\text { ALARA preparation and follow-up, } \\
\text { but no full technical control of the operation }\end{array}$ & $40 \%(30-50)$ \\
\hline $\begin{array}{l}\text { ALARA preparation and follow-up, } \\
\text { and use of feedback data from previous operations }\end{array}$ & $30 \%(15-40)$ \\
\hline
\end{tabular}

Effective dose reduction is most likely to occur if management applies a systematic approach to the application of ALARA. That means to carefully consider all the stages characterising operations, namely preparation, follow-up and feedback analysis [8]. The French studies also contain recommendations for the better integration of ALARA at these different stages, some of which are given below.

\section{Preparation of work}

The preparation phase is certainly one of the most important steps in the process of minimising mishaps and optimising work load. A special attention must be focused on the writing of intervention procedures or work permits. They should be "personalised" according to the specific location where the operation is to take place, by taking into account space constraints and localisation of withdrawal areas. The choice of tools must combine technical and environmental constraints.

Moreover, for operations which are estimated to lead to high exposures, the dosimetry should be predicted phase by phase, using dose rates and intervention time estimates. The person in charge of the operation should be given means to keep track of the real doses and the power to introduce corrective actions if deviations were to be identified. 
C. VIKTORSSON, C. SCHIEBER

\section{Follow-up of work}

The implementation during operations of a systematic data collection network is essential. There are mainly two reasons for that, first to ensure input into so-called past experience data bases and second, to be able to use real time analysis of the causes of deviations from predictions. From an ALARA viewpoint, one should stress the need to collect dosimetric data (collective and individual doses, ambient dose rates, contamination, ...) and information under which conditions the work was carried out (type of personal protection, ergonomics of the working area, ...). Finally, details on mishaps encountered, their causes and impact in terms of time and dose should also be recorded.

\section{Feedback experience}

The constitution of data bases is essential for the rapid diffusion of the lessons learnt, but also for the analysis of the course of the operations. In addition to the above, they have to include information on the individuals involved (level of qualification, training, ...), the description of zones and the elementary tasks carried out, in order to be useful in the preparation of future works.

\section{Management involvement and ALARA programs}

The management approach adopted towards radiation work can have a major influence on the degree of radiation exposure in the workplace. Experience has also shown that effective dose reduction needs firm management involvement and support as well as appropriate dosimetric systems and other tools [6]. In other words, work management, which in this paper is defined as the organisation, control and follow-up of radiation works to ensure that doses are ALARA, is a management issue and must not be left to the radiation protection department alone. The following statement by a representative of the Swiss radiation safety authority may illustrate this :

"The involvement of top management was a very important measure to improve the attitude and awareness for effective radiation protection of all personnel. Radiation protection goals were set up and all the personnel was informed about the importance management attached to the achievement of these goals"[6].

Policy defined by management is not enough, however ; continuous support is needed - a support that has to penetrate and be made known at all levels in the organisation. A key to successfully pursuing ALARA seems to be commitment - a commitment that has to exist at all levels of management, not just at the top level. Many countries have realised this and several of them have defined ALARA programs and some more are in the progress of doing it. In France, for example, the nuclear industry introduced ALARA programs and ALARA committees some years ago. The dosimetric results have improved, 
the collective dose per reactor has gone from 2.4 manSv in 1988 to 2.0 in 1993. The goal for 1995 is 1.6 manSv per reactor. According to Electricité de France $(E d F)$, to be effective the new ALARA culture needs to be [10]:

- predictive : anticipating exposure and the means of reducing it,

- effective : reasonable use of resources given to protection,

- evaluative : taking account of changes in the technical, financial and social context.

For such a management system to succeed, all workers involved must, according to EdF, be motivated, a motivation that should come through a policy of openness with regard to the risks due to radiation and means to making it ALARA.

In Sweden, the occupational doses increased significantly in 1992 and 1993. Reasons for this were large maintenance and repair works, safety requirements, etc. Among the actions taken to turn this negative trend is the introduction of an "ALARA and work management approach". It is believed that such an approach will significantly draw the attention of the management to radiation protection and to the ways in which radiation work is managed and the influence this could have on the safety and economics of the plant. Part of this approach is a regulatory requirement for an ALARA program prepared by each utility. These programs shall contain objectives and dose targets for the short and longer terms, discussions on the basic considerations behind the choice of such objectives and targets, dose reduction plans (source and 'exposure time reductions to be considered) and ways to monitor, follow-up and analyse experience. Finally, the plans shall contain programs for education and training of the workforce as well as the organisational aspects related to all the above [11].

\section{Conclusions}

The nuclear industry has come to a point where greater emphasis on systematic dose reduction is needed. This is not only for the health and safety of the personnel, but also for maintaining the safety and economic viability of the plants and for public acceptance purposes. To succeed, the plant management has to adopt a structured approach to radiation risks and tackle all the factors affecting exposure. The ALARA principle applied through, and by, all levels of management and in all important works seems to be a useful instrument in this respect. Management should deal with doses as they deal with money, i.e. establish systems containing dose targets, mechanisms to follow the results and to take corrective actions, when deviations so require. In this respect it should be pointed out that the dose targets should be challenging but possible to achieve, expressed in measurable terms and accepted by those who are responsible for the results at the company. 


\section{REFERENCES}

[1] BAUM J.W. - Value of public health and safety actions and radiation dose avoided. NUREG/CR-6212, BNL/NUREG-52413, January 1994.

[2] GODÅs T., VIKTORSSON C. - Occupational doses and ALARA. Recent developments in Sweden, In : Proceedings of the 3 . International workshop on implementation of ALARA at nuclear power plants, New York, 1994, NUREG-CP-0143, BNL-NUREG-52440, 347-352.

[3] LOCHARD J., LEFAURE C., SCHNEIDER T. - The economics of radiological protection, In : Proceedings of the 3. International workshop on implementation of ALARA at nuclear power plants, New York, 1994, NUREG-CP-0143, BNL-NUREG-52440, 321-328.

[4] OECD NUCLEAR ENERGY AGENCY (NEA) - Nuclear power plant occupational exposures in the OECD countries, 1969-1992. Paris : OECD, 1994.

[5] OECD NUCLEAR ENERGY AGENCY (NEA) - Expert group on the impact of work management on occupational exposure, a report, Paris : OECD/NEA (to be published).

[6] OECD NUCLEAR ENERGY AGENCY (NEA) - Work management to reduce occupational doses, proceedings of an NEA workshop, Paris, 4-6 February 1992. Paris : OECD, 1992.

[7] OKG AB - Skyddserfarenheter O2/RA 93, 1994 (in swedish).

[8] SCHIEBER C. - ALARA and work management. Westinghouse radiation exposure management seminar, Pittsburgh, 1993.

[9] SCHIEBER C. - Optimisation de la radioprotection et organisation du travail. Report CEPN R- 227, September 1994.

[10] STRICKER L., ROLLIN P., DOLLO R. - Electricité de France's ALARA policy. In : Proceedings of the 3. International workshop on implementation of ALARA at nuclear power plants, New York, 1994, NUREG-CP-0143, BNL-NUREG-52440, 263-274.

[11] WOOD C. - Recent devepments in radiation field control technology. In : Proceedings of the 3. International workshop on implementation of ALARA at nuclear power plants, New York, 1994, NUREG-CP-0143, BNL-NUREG-52440, 9-22. 